\title{
The effect of dietary level of steam treated sugarcane pith on digestibility and ruminal passage rate in Iranian Baluchi sheep
}

\author{
M. Chaji ${ }^{1}$, A.A. Naserian ${ }^{2}$, R. Valizadeh ${ }^{2}$, T. Mohammadabadi ${ }^{1}$, S. TabatabaiVakili ${ }^{1}$ \\ ${ }^{1}$ Ramin (Khuzestan) Agricultural \&Natural Resources University, Molassani-Ahvaz, Khuzestan, Islamic Republic of Iran \\ ${ }^{2}$ Ferdowsi University of Mashhad, Mashhad, Khorasan, Islamic Republic of Iran \\ Email: morteza34312002@yahoo.co.uk
}

Introduction Sugarcane (Saccharum officinarum) is an important crop in the southwest of Iran as well as tropical and subtropical regions of the world. One potential use of sugarcane pith (the fibrous residue following juice extraction and separation of the rind from bagasse) is as a feedstuff for ruminants. The low digestibility, high lignin and very low nitrogen content are considered as the main reasons for unsatisfactory performance of animals fed these roughages. Steam treatments improve voluntary intake and nutritive value of low-quality roughages. In order to better understand the processes of digestion, knowledge of the mean retention time (MRT) and rate of removal of particular components of the diet from gastro-intestinal tract (GIT) is required. In experiments on digestive function in ruminants, markers can be used to estimate the rate of movement of digesta within the GIT. The objective of this study was to evaluate the effect of level of steam treated sugarcane pith (STP) diet inclusion on apparent digestibility of total GIT, and rumen passage parameters.

Material and methods Four Iranian Baluchi wethers (30 $\pm 2 \mathrm{~kg}$ wt.) fitted with rumen (the dorsal sac) and abomasal cannulae were used. They were housed indoors and confined in metabolism cages. The ration was given in equal portions at intervals of $3 \mathrm{~h}$ by an automatic interval feeder. Experimental treatments consisted of 1) the control diet (without STP, STP0), 2) 4\% STP (STP4) 3) 8\% STP (STP8) 4) 12\% STP (STP12) per kg DM of diet, Incremental inclusion of STP replaced wheat bran in the control diet. The experiment was carried out in a change over design; 4 Baluchi wethers were allotted to 4 diets in a $4 \times 4$ Latin square design. The duration of each period consisted of $14 \mathrm{~d}$ of adaptation, $7 \mathrm{~d}$ of total faecal collection, $6 \mathrm{~d}$ of continuous ruminal injection of marker (Cr-EDTA) and $2 \mathrm{~d}$ of rumen fluid sampling. The Cr-EDTA was prepared as described by Binnerts et al. (1968). The abomasal samples were obtained on 2 successive days $\left(5^{\text {th }}\right.$ and $6^{\text {th }}$ d) during marker injection at $3 \mathrm{~h}$ interval. When injection ceased, rumen digesta was collected at $0,3,6,9,12,15,18,24$, $48 \mathrm{~h}$. Using the chemical components of diets and faeces, intake and digestibility of nutrients were calculated. The recommended equations of Weston and Hogan (1967) under steady state conditions were used to calculate passage rate parameters. Digestibility and ruminal digestion kinetics data were statistically analyzed in accordance with a standard latin square design using the GLM procedure of SAS (SAS Inst. Inc., Cary, NC).

Results Intake and apparent digestibility of dry matter (DM) were not affected by treatment but the high pith treatment had the highest digestibility of NDF $(61 \%)$ and ADF $(51 \%)(\mathrm{P}<0.05)$. Ruminal fluid dilution rate (RFDR), rumen turnover time (RTT), ruminal out flow rate (ROFR) and MRT were all affected by treatment in a linear direction $(\mathrm{P}<0.05)$. STP0 in comparison with STP12 had the highest RFDR (8.35 vs. 7.09$)$ and ROFR (0.47 vs. 0.36 L/h) from rumen.

Table 1 Effect of dietary inclusion level of steam treated sugarcane pith on feed intake and diet digestibility

\begin{tabular}{lllllll}
\hline & \multicolumn{4}{c}{ STP $(\mathrm{g} / \mathrm{kg} \mathrm{DM}$ of diet $)$} & \multirow{2}{*}{ s.e.m } & P-Value \\
\cline { 2 - 5 } & 0 & 40 & 80 & 120 & \\
\hline DM intake (g/d) & 831.37 & 823.37 & 860.57 & 839.83 & 11.83 & NS \\
OM intake (g/d) & 775.50 & 769.52 & 801.88 & 780.20 & 15.61 & NS \\
DM digestibility (g/kg) & 600.1 & 604.4 & 605.9 & 629.7 & 6.90 & NS \\
OM digestibility (g/kg) & 696.5 & 700.3 & 714.1 & 740.3 & 4.90 & NS \\
NDF digestibility (g/kg) & $507^{\mathrm{a}}$ & $540.1^{\mathrm{b}}$ & $563.7^{\mathrm{b}}$ & $608.8^{\mathrm{c}}$ & 6.90 & $\mathrm{~L}^{*}$ \\
ADF digestibility (g/kg) & $429.9^{\mathrm{a}}$ & $467^{\mathrm{ab}}$ & $497.8^{\mathrm{b}}$ & $568.9^{\mathrm{c}}$ & 11 & $\mathrm{~L}^{*}$ \\
\hline \hline
\end{tabular}

OM: Organic matter; L: Linear effect; NS: Non significant; $* \mathrm{P}<0.05$

Table 2 Effect of dietary inclusion level of steam treated sugarcane pith on ruminal digestion kinetics

\begin{tabular}{|c|c|c|c|c|c|c|}
\hline & \multicolumn{4}{|c|}{ STP (g/kg DM of diet) } & \multirow[t]{2}{*}{ s.e.m } & \multirow[t]{2}{*}{ Effect } \\
\hline & 0 & 40 & 80 & 120 & & \\
\hline Ruminal fluid dilution rate $(\% / \mathrm{h})$ & $8.53^{\mathrm{a}}$ & $7.66^{b}$ & $7.42^{b}$ & $7.09^{\mathrm{b}}$ & 0.22 & $\mathrm{~L}^{*}$ \\
\hline Rumen turnover time $(\mathrm{h})$ & $11.97^{\mathrm{b}}$ & $13.14^{\mathrm{a}}$ & $13.53^{\mathrm{a}}$ & $14.17^{\mathrm{a}}$ & 0.34 & $\mathrm{~L}^{*}$ \\
\hline Ruminal Outflow rate $(\mathrm{L} / \mathrm{h})$ & $0.47^{\mathrm{a}}$ & $0.397^{\mathrm{ab}}$ & $0.374^{\mathrm{b}}$ & $0.36^{\mathrm{b}}$ & 0.03 & $\mathrm{~L}^{*}$ \\
\hline MRT (h) & $12.39^{\mathrm{b}}$ & $13.19^{\mathrm{ab}}$ & $13.50^{\mathrm{a}}$ & $14.03^{\mathrm{a}}$ & 0.40 & $\mathrm{~L}^{*}$ \\
\hline
\end{tabular}

L: Linear effect; NS: non significant; MRT: Mean retention time; ${ }^{\mathrm{P}<0.05}$

Conclusion The results of this experiment suggest that STP can be included up to $12 \%$ of dietary DM and leads to lower ROFR, RFDR and RTT and higher MRT when compared with a wheat bran based diet (STP0). The greater digestibility of NDF and ADF fractions suggest that steam treatment can improve the nutritive value of sugarcane pith.

\section{References}

Binnerts, W.T., Van't Klooster, A.Th. and Frens. A.M. 1968. Veterinary Record 28, 470.

Weston, R.H. and Hogan, J.P., 1967. Australian Journal of Agricultural Resources 18, 789-801. 